\title{
СПУТНИКИ, ОРБИТЫ И ЧАСТОТЫ в реалиях-2020
}

л.Павлова

DOI: $10.22184 / 2070-8963.2020 .92 .7-8.48 .50$

Тенденции развития цифровых технологий и вопросы трансформации спутниковой связи под влиянием пандемии COVID-19, будущее отрасли в современных реалиях, развитие услуг на базе 5G, проблемы вещательной и медиаиндустрий - темы XXV-й международной конференции операторов и пользователей сетей спутниковой связи Российской Федерации SATCOMRUS 2020, проведенной в этом году в режиме онлайн.

В работе традиционного, 25-го по счету, спутникового форума, организованного ФГУП "Космическая связь" (ГП КС) при поддержке Министерства цифрового развития, связи и массовых коммуникаций Российской Федерации (Минцифры России), Федерального агентства связи (Россвязь) и Госкорпорации "Роскосмос", приняли участие более 400 специалистов России, Великобритании, США, Канады, Израиля, Италии, Франции, Индонезии, Нигерии, Индии, Азербайджана. Мероприятие открыла заместитель генерального директора ГП KC, председатель эксплуатационного комитета МОКС "Интерспутник" Ксения Дроздова, выступившая в роли модератора пленарной сессии. Она отметила, что события 2020 года, связанные с пандемией, одновременно стали и вызовом, и источником новых возможностей для всех отраслей мировой экономики, в первую очередь для телекома и спутниковой отрасли. "Согласно отчету Международной ассоциации спутниковой связи, общая выручка спутниковой индустрии от предоставления услуг в 2019 году составила 123 млрд долл. США, - сообщила К.Дроздова. - По оценке экспертов, спутниковым операторам для того, чтобы вернуться к докризисным показателям 2019 года, потребуется порядка трех лет. Пандемия сильнее всего ударила по драйверам роста - морским перевозкам, воздушным перелетам и Backhauling. Достаточно сказать, что на конец 2019 года порядка 9200 самолетов были оборудованы доступом к интернету, и сейчас из-за пандемии эксперты прогнозируют снижение доходов в этом сегменте примерно на 30\%". В то же время эксперты прогнозируют, что к 2029 году число подключенных бортов удвоится, и выручка операторов спутнико вой отрасли составит порядка 250 млрд долл. "В это очень сложно поверить на фоне массового банкротства операторских компаний, которые, к сожалению, не выдерживают испытаний пандемией, - прокомментировала К.Дроздова. - Но все равно экспертное сообщество оптимистично. То есть, мы наблюдаем абсолютно разнонаправленные тренды, и чрезвы ${ }^{-}$ чайно интересно в этот момент послушать наших экспертов относительно их видения будущего спутниковой связи".

Как показала SATCOMRUS 2020, доминирует во всех эшелонах российской отрасли спутниковой связи конструктивный оптимизм. Заместитель министра цифрового развития, связи и массовых коммуникаций РФ Олег Иванов отметил, что роль и место спутниковой связи в развитии и обеспечении телекоммуникационными услугами Российской Федерации трудно переоценить: "Иногда создается впечатление, что спутниковая связь создана для российских просторов, и если бы ее не было, то никакой речи об устранении цифрового неравенства не приходилось бы вести. Значимость отрасли непреходяща". Тем не менее, при реализации "Цифровой экономики" возникают определенные вопросы к отрасли спутниковой связи, что связано с двумя основными факторами, отметил О.Иванов. Во-первых, это качество 
и доступность услуг: многие регионы, особенно отдаленные, такие как Чукотка и Якутия, постоянно обращаются за возможностью улучшения качества услуг в плане наращивания скорости, а также устойчивости спутниковой связи при воздействии погодных условий. Во-вторых - и это понятная проблема, которая постоянно звучит в обращениях регионов, - стоимость услуг спутниковой связи. "Не всегда эта проблема зависит от спутниковых операторов, более глубокое исследование показывает, что она кроется и в ценах наземных интеграторов, - считает О.Иванов. - Каковы пути решения этих проблем? И теория, и практика подсказывают, что других путей, кроме как увеличение возможности конкуренции на этом рынке и наращивание общего объема предлагаемых услуг, не существует. А это напрямую зависит от развития отрасли, от запуска новых космических аппаратов, от перехода в перспективные радиочастотные диапазоны и применения новых орбит спутниковой связи, которые бывают хорошо забытыми старыми, и других специфических, иногда технических, факторов".

Руководитель Россвязи Олег Духовницкий в докладе "Роль и место спутниковой связи в цифровой экономике Российской Федерации" подчеркнул, что проект многоспутниковой системы связи на высокоэллиптических орбитах "Экспресс-РВ", который включен в подпрограмму "Сфера" национальной программы "Цифровая экономика Российской Федерации", позволит обеспечить практически повсеместный высокоскоростной доступ к цифровым услугам связи, в том числе к сети Интернет, на всей территории страны, включая малонаселенные пункты с численностью менее 250 человек и удаленные населенные пункты Крайнего Севера, Сибири и Дальнего Востока.

Руководитель ФГУП "Космическая связь" Юрий Прохоров подробно рассказал о направлениях деятельности предприятия, которые в среднесрочной перспективе окажут влияние на развитие отечественной отрасли спутниковой связи, включая состоявшиеся и запланированные запуски. Как известно, в конце июля состоялся запуск двух новых спутников: "Экспресс-80" (80 в. д.) и "Экспресс-103" $\left(96,5^{\circ}\right.$ в. д.). Сейчас они находятся на переходной орбите, а начало их коммерческой эксплуатации ожидается в январе-феврале 2021 года. Запуск следующих двух КА - "Экспресс-АМУз" и "Экспресс-АМУ7" - намечен на 2021 год. В настоящее время специалисты ГП КС ведут проработку облика нового КА "ЭкспрессАМУ4". Ю.Прохоров подчеркнул, что предприятие внимательно следит за мировыми трендами и учитывает их в портфеле своих услуг. Это и гибкие полезные нагрузки на геостационарных спутниках, и проекты многоспутниковых группировок связи на негеостационарных орбитах, и Интернет вещей, а также предоставление услуг связи на подвижных объектах. Именно эти решения для развития цифровой экономики заложены в новые космические аппараты ГП КС. Руководитель предприятия также сообщил о результатах развития собственных услуг добавленной стоимости ГП КС в области вещания и связи на подвижных объектах, где, несмотря на пандемию и глобальный локдаун, оператору удалось сохранить лидирующие позиции на отечественном и зарубежном рынках. Останавливаясь на экономических показателях, Ю.Прохоров отметил, что на фоне просевшей мировой спутниковой отрасли ГП КС смотрится очень неплохо: в 2020 году выручка предприятия составит 12,3 млрд руб., то есть на уровне 2019 года. Принимая во внимание очень тяжелое положение, в которое попала мировая космическая отрасль, такой результат представляется вполне успешным.

Юрий Вилков, заместитель генерального директора - заместитель генерального конструктора по развитию и инновациям АО "Информационные спутниковые системы" имени академика М.Ф.Решетнева", рассказал о том, как предприятия, занимающиеся разработкой и созданием спутников, реагируют на новые вызовы времени. Говоря о текущем состоянии развития спутниковых технологий, Ю.Вилков отметил следующие достижения: модульное построение космических аппаратов; стандартные интерфейсы, позволяющие использовать оборудование различных производителей; возможность интеграции с полезными нагрузками различных производителей; тандемный запуск двух космических аппаратов (КА); довыведение спутников на ГСО с помощью электрореактивных двигателей (до 4,5 т); мощность, выделяемая на полезную нагрузку более 6 кВт (для средней платформы) и более 12 кВт для тяжелой; собственное производство полезных нагрузок и оборудования полезных нагрузок. В качестве основных направлений совершенствования космических аппаратов докладчик указал: повышение гибкости технических решений для выполнения требований заказчиков КА; сокращение стоимости проектирования и изготовления КА; создание научно-технического задела по перспективным технологическим направлениям; повышение технологической готовности предприятия; развитие производственной базы предприятия, реализация технологии серийного изготовления космических аппаратов. Ближайшие цели предусматривают: создание универсального оборудования; развитие платформ для ГСО; создание платформы для КА на высоком эллипсе; создание КА для многоспутниковых группировок. На площадке 
SATCOMRUS 2020 Решетневская фирма сформулировала главные задачи, стоящие перед производителем космической техники: создавать спутники, способные обеспечивать связь в разных диапазонах частот на различных орбитах; предлагать гибкие решения для потребителей; постоянно развивать технологии и производство.

Другой центральной темой конференции стали вопросы стандартизации 5С и роли спутниковой связи в развитии экосистемы 5С. Сегодня во всем мире остро стоит вопрос о высвобождении частотных диапазонов для развития сетей мобильной связи пятого поколения. Администрации связи разрабатывают соответствующие планы, международные организации прорабатывают вопросы стандартизации спутникового компонента 5С. Ключевые спикеры из организаций, разрабатывающих новые стандарты связи - Виктор Стрелец (МСЭ), Саша Сироткин (3СРР) - рассказали о текущем статусе разработки стандартов сетей связи пятого поколения. Свое видение относительно перспективы развития сетей 5С в России представил также заместитель директора Департамента государственной политики в сфере связи Минцифры России Андрей Жеглов. Напомним, что летом этого года компания МТС первой из российских сотовых операторов получила лицензию на использование частотного диапазона для развертывания сетей 5С в 83 субъектах РФ. Надзорные органы выделили полосу стандарта IMT-2020, где используются высокие частоты 24,25-24,65 ГГц. Но более низкие частотные диапазоны, ниже 6 ГГц, доступные для 5С под гражданскую связь, пока не удается задействовать. Они задействованы силовиками. А с высокочастотными 5С - это как раз от 24 до 40 ГГц - множество проблем. А.Жеглов отметил, что поиск свободных частот является первым этапом внедрения любой новой технологии радиосвязи, так что сети пятого поколения не являются тут исключением из общего правила. Но если при внедрении сотовых сетей 2С и 3С частоты находились довольно быстро, то уже с приходом 4G/LTE регуляторам пришлось пойти на различные ухищрения, как административные, так и технические. "Найти необходимый частотный ресурс для сетей 5 С без работ по конверсии невозможно, - уверен А.Жеглов. - В перспективе план министерства заключается в том, чтобы выделить полосу частот единому инфраструктурному оператору и продолжать работы по конверсии спектра, по поиску свободного ресурса".

Участники сессии "Глобальная перезагрузка вещательной и медиаиндустрии" - представители медиаи ИТ-компаний, обсудили проблемы отрасли и изменения на медийном рынке, в том числе и влияние пандемии COVID-19. В последние годы было много разговоров об изменениях на рынке телевидения и медиа. С одной стороны, эксперты и игроки рынка так или иначе признавали тот факт, что существующие модели продвижения контента и сервисов умирают с появлением новых технологий и изменением формата потребления. С другой стороны, крупные операторы связи и медиахолдинги воздерживались от серьезного пересмотра стратегий, полагаясь на привычные бизнес-модели. Участники дискуссии обсудили и то, как глобальный мировой экономический кризис, связанный с пандемией COVID-19, поменял расстановку сил на рынке медиаконтента.

В рамках сессии "Низкоорбитальные системы и развитие систем спутниковой связи: планы российских операторов спутниковых систем. Рынки VSAT и НГСО. Негеостационарные спутниковые системы для телеком-бизнеса" представители российских и зарубежных спутниковых операторов и производителей поделились своими планами по развитию бизнеса в низ коорбитальных системах спутниковой связи, а также рассказали об уже готовых решениях и технологических новинках в сегменте спутникового пользовательского оборудования. Николай Орлов, региональный вице-президент по России Eutelsat S.A., представил проект ELO - низкоорбитальной системы связи компании Eutelsat.

Валентин Анпилогов, заместитель генерального директора ЗАО "ВИСАТ-ТЕЛ", проанализировал перспективы развития многоспутниковой системы передачи данных с использованием низкоорбитальной группировки микроспутников массой 45-50 кг "Марафон ІоТ" в условиях конкурентоспособности услуг и сервисов. Система ориентирована на новый рынок для спутниковой связи, который оценивается в перспективе более чем в десяток миллиар дов долларов в год. Ее целевая функция - Интернет вещей с эксплуатационными и ценовыми параметрами услуги, соизмеримыми с наземными сетями. По сути, это одна из информационных основ искусственного интеллекта. В качестве опций заявлены задачи контроля беспилотных систем, АЗН-В, АИС и трансляция дифференциальных поправок к навигационным сигналам. Отличается "Марафон IоT" от спутниковых систем связи тем, что в качестве каналообразующего протокола и абонентских устройств применяются, по сути, те же решения, что и в сетях LoRaWAN. Система "Марафон IoT" входит в подпрограмму "Сфера", но финансирования пока нет. Однако работы по ее созданию уже начались в кооперации: ЗАО "ВИСАТ-ТЕЛ" отвечает за земной сегмент и системные решения, АО "ИСС имени академика М.Ф.Решетнева" разрабатывает космический 
сегмент, МФТИ - оконечные устройства и ПО приложений, ФГУП НИиР - модули полезной нагрузки на спутнике, НП ГЛОНАСС - приложения для "кнопки жизни". В проекте участвуют еще примерно 15 компаний, и кооперация постоянно расширяется.

Сергей Степаненко, технический директор ГK AltegroSky, завершил сессию докладом на тему "Корпоративный рынок VSAT. Точки экстремума в 2020 году". Он рассказал об адаптации спутникового оператора к изменениям рынка и способах формирования новой стратегии, отвечающей цифровой трансформации задач потребителей. С.Степаненко отметил, что негативные факторы, с которыми столкнулись российские спутниковые провайдеры в 2020 году, - карантинные ограничения, экономические последствия пандемии, отключение сервисов на "Экспресс-АM6" - привели к тому, что спутниковым операторам пришлось "оперативно вносить изменения в собственные стратегии и направлять основные ресурсы на ускорение развития приоритетных направлений". В качестве примера был приведен опыт ГK Altegrosky, когда в начале весеннего локдауна компанией на основе собственных возможностей и ресурсов был предпринят ряд мер, которые позволили оказать поддержку корпоративным клиентам ключевых отраслей, столкнувшихся с негативным влиянием глобальных экономических последствий пандемии или оказавшихся под давлением международных соглашений ОРЕС+. Для преодоления карантинных ограничений параллельно была проведена работа по реорганизации взаимодействия с региональными партнерами, взявшими на себя немалый объем работ. Активные действия коллег и их высокая квалификация позволили в рабочем режиме продолжить проведение монтажа и сервисного обслуживания станций клиентов в удаленных регионах. Однако приоритетной задачей компании стал поиск новых точек роста. С.Степаненко отметил, что в рамках расширения портфеля услуг спутникового оператора наиболее привлекательной и высокопотенциальной является область пересечения VSAT-технологий и основных направлений цифровизации ключевых отраслей. На этом пути VSAT должен стать частью среды передачи данных, как одна из возможных технологий для имплементации ИТ-решений. Таким образом, резюмировал эксперт, дальнейшее устойчивое развитие спутни кового оператора неразрывно связано с наращиванием компетенций и опыта на стыке цифровизации и телекома, а также с построением экосистемы вокруг клиента с применением как спутниковых, так и других технологий связи.

В завершение конференции состоялась церемония награждения отраслевой премией SATCOMRUS AWARDS 2020 и подведение итогов маркетинговой акции "К 75-летию Победы", организованной ГП КС совместно с партнерами по ССВД и Ka-band. Оргкомитет конференции выразил благодарность генеральным партнерам конференции - MOKC "Интерспутник" и АО "Информационные спутниковые системы" имени академика М.Ф.Решетнева", стратегическим партнерам ФГУП РТРС и Eutelsat, а также компаниям "Исател", "Ка-Интернет", Hughes, Gilat, AltegroSky, Thales Alenia Space, "Морсвязьспутник", РТКОММ, КБ "Искра" и "ТМТ Conference", которые уже на протяжении многих лет являются партнерами SATCOMRUS.

\section{"Газпром космические системы" и Axelspace сотрудничают по проектам наблюдения Земли для энергетического сектора}

Компания "Газпром космические системы" и корпорация Axelspace (Япония) подписали меморандум о взаимопонимании, предусматривающий совместную работу с целью расширения возможностей по использованию данных наблюдения Земли и принятию информированных решений.

Axelspace и"Газпром КС" подписали данный меморандум при активной поддержке Mitsui \& Co. LTD и Mitsui \& Co. Moscow LLC, чтобы изучить возможности предоставления конкурентоспособных решений дистанционного зондирования, особенно для энергетической отрасли, путем совместного использования спутниковых снимков, полученных от платформы AxelClobe компании Axelspace (основой которой является собственная группировка микроспутников CRUS), и снимков, которые будет поставлять космическая система дистанционногозондирования Земли СМОТР на базе спутников СМОТР-В.

AxelClobe - это платформа наблюдения за Землей нового поколения, состоящая из десятков микроспутников под названием CRUS. Первый спутник CRUS был запущен в декабре 2018 года, и его данные начали предоставляться широкому кругу клиентов с мая 2019 года. Приложения варьируются от сельского хозяйства до мониторинга стихийных бедствий, городского планирования и управления земельными ресурсами. Axelspace готов к запуску еще четырех спутников CRUS в бли- жайшее время, что позволит значительно увеличить периодичность наблюдения объектов.

Система СMOTP разрабатывается компанией "Газпром КС" (дочерним предприятием ПАО "Газпром"), которая осуществляет космическую деятельность в области создания и эксплуатации телекоммуникационных и геоинформационных космических систем в интересах компаний Группы Газпром и других заказчиков. Основная задача системы - мониторинг газовой инфраструктуры и экологический мониторинг.

По информации компании "Газпром космические системы" 


\section{ГЛАВНОЕ}

СОБЫТИЕ ОТРАС́ЛИ

ИНФОРМАЦИОННОЙ БЕЗОПАСНОСТИ
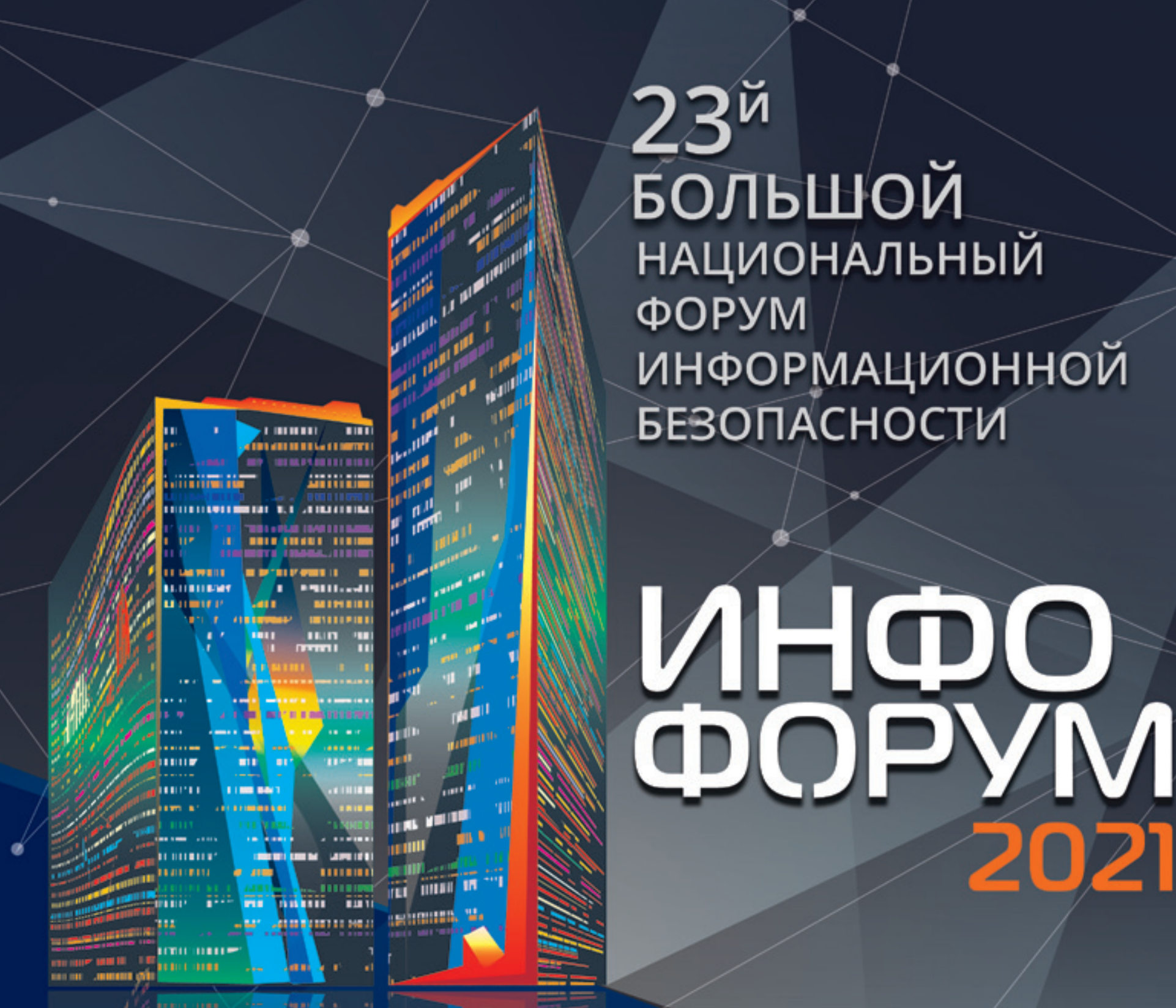

ПРЕОДОЛЕНИЕ РИСКОВ ИНФОРМАЦИОННОЙ БЕЗОПАСНОСТИ В ЦИФРОВУЮ ЭПОХУ

\section{5 февраля}

Здание Правительства Москвы ул, Новый Арбат, 36 